\title{
Effects of Chemical Uncouplers on Microbial Biomass Production, Metabolic Activity, and Community Structure in an Activated Sludge System
}

\author{
AKIRA HIRAISHI ${ }^{1 *}$ and TOMOKI KAWAGISHI ${ }^{1}$ \\ ${ }^{1}$ Department of Ecological Engineering, Toyohashi University of Technology, Toyohashi 441-8580, Japan
}

(Received August 5, 2002-Accepted September 16, 2002)

Recent reports have suggested the usefulness of a metabolic uncoupler to reduce excess sludge production in the activated sludge process. This study was conducted to more thoroughly study the effects of different chemical uncouplers on microbial biomass production, metabolic activity, and community structure in a laboratoryscale activated sludge system fed with synthetic sewage. Results showed that the amount of biomass produced decreased sharply with increasing concentrations of uncouplers in all cases. Among the five congeners of chlorophenols and nitrophenols as uncouplers studied, 4-nitrophenol was the most effective in reducing biomass production. The addition of $200 \mu \mathrm{M}$ 4-nitrophenol resulted in a reduction in the biomass yield to less than $10 \%$ compared the control culture without the additive, while the BOD removal efficiency with the uncoupler remained approximately $80 \%$ of the control level. Differences in biomass reduction efficiency among the uncouplers tested suggested that uncouplers with a lower $\mathrm{p} K_{\mathrm{a}}$ value have a higher potential to reduce biomass production. A short-term sequencing batch cultivation of sludge with any uncoupler exerted no or little effect on respiratory enzyme activities and the microbial community structure of the sludge. When the inhibitory effect of 4-nitrophenol on biomass production was studied in prolonged sequencing batch cultures, it was found to gradually diminish with time and had almost vanished after 4 weeks of operation. At this stage, a significant change in microbial community structure was demonstrated by respiratory quinone profiling. These results indicate that dosing an uncoupler in a short period is useful for minimizing excess sludge production in the activated sludge process without a significant decrease in BOD removal efficiency, but this positive effect is questionable over a long period of operation.

Key words: uncouplers, nitrophenol, chlorophenol. activated sludge

Biomass production in the activated sludge process has for a long time been and still is a research subject of major concern, because how to dispose of the resultant excess sludge is one of the most challenging problems in wastewater treatment technology. Bacteria are the major constituents of the biomass in this process, and their population levels depend upon a number of operational and environmental factors. The availability of organic matter as expressed by biochemical oxygen demand (BOD) is the primary factor affecting the amount of bacterial biomass in the process, as

\footnotetext{
* Corresponding author; E-mail: hiraishi@eco.tut.ac.jp, Tel: +81532-44-6913, Fax: +81-532-44-4929
}

BOD elements are utilized directly as carbon and energy sources for bacterial growth. Biological interactions in the food web are also important factors controlling bacterial population size and dynamics, although information on this subject has not yet been accumulated. Probably, the main biological factors involved are bacteriophage infection, bacterial predation, and grazing by protozoa and metazoa.

While a number of approaches to the disposal of excess sludge in the activated sludge process have been considered ${ }^{6,30,32,37)}$, bioenergetic metabolism in this process has recently received more attention to exploit a biochemical technique to minimize biomass production. Several workers have challenged the application of chemical uncou- 
plers for regulating biomass production in the activated sludge process ${ }^{5,6,21-23)}$. Metabolic uncouplers, represented by chlorophenol (CP) and nitrophenol (NP) compounds, are all lipophilic protonophores and are able to uncouple the link of respiratory electron transport and proton translocation across the cytoplasmic membrane ${ }^{9}$.

The electron transport-linked proton translocation results in the generation of the proton motive force (PMF), which is essential to entail oxidative phosphorylation ${ }^{27)}$. The PMF is given by:

$$
\mathrm{PMF}=\Delta \Psi-2.3 R T \Delta \mathrm{pH} / F
$$

where $\Delta \Psi$ and $\Delta \mathrm{pH}$ are the electrochemical potential and the $\mathrm{pH}$ gradient across the cytoplasmic membrane, respectively. $\Delta \mathrm{pH}$ has a negative value, and therefore, PMF has a positive one. Uncouplers can diffuse relatively freely though the membrane and release a proton inside the membrane. Therefore, the addition of uncoupler to the microbial culture will result in a shift of $\Delta \mathrm{pH}$ to a positive value, thereby diminishing PMF significantly or even to zero. Eventually, the microorganism is unable to produce ATP in the presence of the uncoupler, although the electron transfer velocity itself in their respiratory chain would be stimulated by uncoupling. This means the possibility that microbial growth yield in an activated sludge system is reduced by uncoupling without a marked decrease of substrate oxidation rate, i.e., BOD removal performance. In fact, a previous study showed that no excess sludge was produced in the presence of an uncoupler, 4-nitrophenol (4NP), at a concentration of $120 \mathrm{mg} \cdot l^{-122)}$.

Although the uncoupling biochemical process may minimize excess biomass production in activated sludge systems, there remain the questions of whether this method is effective from a practical point of view and of whether the addition of an uncoupler exerts negative effects on metabolic activity and the community structure of sludge. Bacterial resistance to uncouplers has been well reviewed ${ }^{19,20)}$. Also, several species of bacteria or activated sludge have been reported to degrade chemicals that may act as uncouplers $^{2-4,7,15,25,28,29,33,34)}$. Thus, this paper focuses on the effects of different metabolic uncouplers on microbial biomass production, metabolic activity, and community structure in an activated sludge system. The effectiveness of the uncoupler method for reducing microbial biomass in the activated sludge process is discussed from ecological and practical points of view.

\section{Materials and Methods}

\section{Chemical used}

The uncouplers used in this study were carbonyl cyanide $m$-chlorophenyl hydrorazone (CCCP), 3-chlorophenol (3CP), 4-chlorophenol (4CP), 3-nitrophenol (3NP), 4NP, and 2,4-dinitrophenol (DNP) (Table 1), all of which were purchased from Sigma (St. Louis, MI). All these chemicals were prepared as 20 to $200 \mathrm{mM}$ stock solutions in dimethylsufoxide and stored at $-20^{\circ} \mathrm{C}$ until use. When used, these solutions were diluted with $10 \mathrm{mM}$ phosphate buffer $(\mathrm{pH}$ 7.0) and neutralized with $\mathrm{KOH}$ as needed. All other chemicals used were obtained from Sigma and Wako Pure Chemical Industries (Osaka, Japan).

\section{Activated sludge}

Activated sludge was collected from a sewage treatment plant in Toyohashi, Japan, and used as the seed sludge for laboratory-scale reactors. The laboratory activated sludge system, consisting of five glass bottles (2-l capacity) equipped with magnetic stirrers, an air pomp, and a dissolved oxygen (DO) controller, was operated on a fill-anddraw basis ( $24 \mathrm{~h}$-batch cycle) with synthetic sewage ${ }^{10)}$ as the wastewater. The operational conditions were as follows: culture volume, 1,000 ml; mixed liquor suspended solids (MLSS), 2,000 $\mathrm{mg} \cdot l^{-1}$ (at the start of each batch cycle); BOD-loading rate, $0.32 \mathrm{~g}$ BOD.g $\mathrm{MLSS}^{-1} \cdot \mathrm{d}^{-1}$; temperature, $25^{\circ} \mathrm{C}$; DO tension, $2.0-3.0 \mathrm{mg} \cdot l^{-1}$; stirring speed, $60 \mathrm{rpm}$ $\mathrm{min}^{-1}$. At the end of every batch cycle, half of the supernatant obtained after 30 min of sedimentation was exchanged with "fresh" synthetic sewage. The reactors were acclimated to synthetic sewage at least for 2 months before experiments with uncouplers.

Table 1. Chemical uncouplers used ${ }^{\mathrm{a}}$

\begin{tabular}{lccc}
\hline \multicolumn{1}{c}{ Uncoupler (and abbreviation) } & $\begin{array}{l}\text { Chemical } \\
\text { formula }\end{array}$ & $\mathrm{MW}$ & $\mathrm{p} K_{\mathrm{a}}$ \\
\hline $\begin{array}{l}\text { Carbonyl cyanide } m \text {-chlorophenyl } \\
\text { hydrazone (CCCP) }\end{array}$ & $\mathrm{C}_{9} \mathrm{H}_{5} \mathrm{ClN}_{4}$ & 204.6 & 5.9 \\
3-Chlorophenol (3CP) & $\mathrm{C}_{6} \mathrm{H}_{5} \mathrm{ClO}$ & 128.56 & 9.12 \\
4-Chlorophenol (4CP) & $\mathrm{C}_{6} \mathrm{H}_{5} \mathrm{ClO}$ & 128.56 & 9.41 \\
2-Nitrophenol (2NP) & $\mathrm{C}_{6} \mathrm{H}_{5} \mathrm{NO}_{3}$ & 139.11 & 7.23 \\
3-Nitrophenol (3NP) & $\mathrm{C}_{6} \mathrm{H}_{5} \mathrm{NO}_{3}$ & 139.11 & 8.36 \\
4-Nitrophenol (4NP) & $\mathrm{C}_{6} \mathrm{H}_{5} \mathrm{NO}_{3}$ & 139.11 & 7.15 \\
2,4-Dinitrophenol (DNP) & $\mathrm{C}_{6} \mathrm{H}_{4} \mathrm{~N}_{2} \mathrm{O}_{5}$ & 184.11 & 4.09 \\
\hline${ }^{\mathrm{a}}$ Information from Heytler & and & the $\mathrm{H}_{2} \mathrm{Hardous}^{9}$ & Substances Data \\
Bank ${ }^{36)}$. & & &
\end{tabular}




\section{Batch cultures with uncouplers}

The reactors fully acclimated to synthetic sewage were subsequently operated for one week under the same condition as noted above, except that an uncoupler solution was added with "fresh" synthetic sewage at the start of every batch cycle. The final concentrations of uncoupler added were 5-20 $\mu \mathrm{M}$ for CCCP, $10-100 \mu \mathrm{M}$ for DNP, 20-200 $\mu \mathrm{M}$ for $4 \mathrm{NP}$, and $200 \mu \mathrm{M}$ for the others. In addition, an activated sludge reactor was operated for more than one month with $200 \mu \mathrm{M} 4 \mathrm{NP}$ to study its effect over a long period of operation. At the end of every batch cycle, the supernatant was collected and subjected to MLSS and BOD analyses. The apparent yield coefficient $\left(Y_{\mathrm{X} / \mathrm{S}}\right)$ was determined based on the ratio of the MLSS increased $(\Delta X)$ to the BOD consumed $(\Delta S)$ per day. MLSS and BOD were measured according to standard methods ${ }^{1}$. In some cases, $4 \mathrm{NP}$ in the supernatant was measured by ion-pair high-performance liquid chromatography with a reverse-phase column as described previously ${ }^{33)}$.

\section{Total counts}

For counting the total cell number, sludge samples taken from the reactors were fixed with $1 \%$ formalin, sonicated on ice for $1 \mathrm{~min}(20 \mathrm{kHz}$; output power $50 \mathrm{~W})$, and then diluted appropriately with filter-sterilized $50 \mathrm{mM}$ phosphate buffer (pH 7.5). Total bacterial counts were measured by epifluorescence microscopy with ethidium bromide $(\mathrm{EtBr})$ or SYBR Green II staining as described previously ${ }^{16,31)}$. After 5 min of staining, the samples were washed gently with cold pure water and observed under an Olympus BX-50 epifluorescence microscope equipped with a Flovel model FD120M digital CCD camera (Flovel Co., Tokyo, Japan).

\section{Assay of oxygen uptake}

For measurement of oxygen consumption, sludge samples were harvested by centrifugation, washed twice with 50 $\mathrm{mM}$ phosphate buffer ( $\mathrm{pH} 7.5$ ), and resuspended in small volumes of this buffer. The washed sludge suspension was introduced into the reaction chamber (2-ml capacity) of an Iijima model B-505 DO meter with a polarograph-type oxygen macroelectrode (Iijima Electronics Co., Tokyo, Japan). The reaction chamber was stirred on a magnetic stirrer and incubated at $25^{\circ} \mathrm{C}$ until the DO uptake rate with endogenous substrates became stable. Thereafter, $20 \mu \mathrm{l}$ of synthetic sewage as an exogenous substrate was added to the reaction chamber, and DO consumption was further monitored. After 1-2 min of monitoring, an uncoupler solution (final concentration, 5-200 $\mu \mathrm{M}$ ) was added to the reaction chamber to see its effect on DO consumption. The same volume of DMSO was used as the control additive. Finally, $1 \mathrm{mM}$ $\mathrm{KCN}$ freshly prepared was added to stop the aerobic respiration.

\section{Assays of respiratory enzyme activities}

Sludge samples were collected, washed, and concentrated in $50 \mathrm{mM}$ phosphate buffer ( $\mathrm{pH}$ 7.5) as noted above. Then the concentrated sludge suspensions were sonicated for 3 min with a $2 \mathrm{sec}$ intermittent burst $(20 \mathrm{kHz}$; output power, $150 \mathrm{~W}$ ) and centrifuged at $20,000 \times g$ for $20 \mathrm{~min}$ to remove unbroken sludge and large debris. The resultant cell-free extract was immediately used for enzyme assays. All these procedures were performed at $4^{\circ} \mathrm{C}$ or on ice. All enzymic activities were measured spectrophotometrically with a Hitachi U-2000 spectrophotometer equipped with a thermocontroller unit at $25^{\circ} \mathrm{C}$. NADH oxidase activity was determined with the cell-free extract by following the rate of reduction of NADH at $340 \mathrm{~nm}$ according to the protocol of Mannheim et al. ${ }^{24)} \mathrm{NADH}$ dehydrogenase (EC 1.6.99.3) and succinate dehydrogenase (EC 1.3.99.1) were assayed with the cell-free extract by following the rate of reduction of 2,6-dichlorophenolindophenol (DCIP) at $578 \mathrm{~nm}$ according to the protocol of King and Drews ${ }^{17)}$. Nitrate reductase and denitrification activities were measured with intact cell suspensions by a modification ${ }^{35}$ ) of the method of Krisjansson and Hollocher ${ }^{18)}$. One unit of enzymic activity was defined as the amount of enzyme that catalyzes $1 \mu \mathrm{mol}$ of substrate per min at $25^{\circ} \mathrm{C}$. Protein was measured colorimetrically by the Lowry method modified by Hartree ${ }^{8)}$ with bovine serum albumin as the standard.

\section{Quinone profiling}

Quinones from washed sludge samples were extracted with a chloroform-methanol mixture and fractionated into the menaquinone and ubiquinone fractions by column chromatography using Sep-Pak ${ }^{\circledR}$ cartridges (Waters Corp., Milford, MA). Quinone components were separated and identified by reverse-phase HPLC and photodiode array and mass spectrometry detection with external quinone standards. Detailed information on these analytical procedures has been given previously ${ }^{13,14}$. Differences in the quinone profile among sludge samples were expressed by using the dissimilarity index $(D)^{12)}$, which was calculated using the BioCLUST program ${ }^{14)}$. 


\section{Results}

\section{Effects on oxygen uptake}

The uncoupler method for minimizing excess sludge is based on the principle that uncouplers diminish the electrochemical potential and the $\mathrm{pH}$ gradient across the membrane without the inhibition of respiratory electron transport resulting from substrate oxidation. As a result of uncoupling, the electron transfer velocity, i.e., DO uptake rate, is rather stimulated ${ }^{27}$. Thus, preliminary experiments were performed to determine the minimum concentration of uncouplers that stimulates DO consumption by activated sludge. An example of the DO uptake profile of activated sludge in response to 4NP and other additives is shown in Fig. 1. We found that concentrations of uncouplers high enough to stimulate the DO uptake rate were $10 \mu \mathrm{M}$ for CCCP, $100 \mu \mathrm{M}$ for DNP, and $200 \mu \mathrm{M}$ for the others.

\section{Effects on biomass production and BOD removal}

The effects of different concentrations of CCCP, DNP, and 4NP on biomass production and BOD removal in 24-h batch cultures of activated sludge are shown in Fig. 2. In all cases, the biomass production in terms of $Y_{\mathrm{X} / \mathrm{s}}$ decreased sharply with increasing concentrations of the uncouplers. The $Y_{\mathrm{X} / \mathrm{s}}$ value became almost zero in the presence of $20 \mu \mathrm{M}$ CCCP, $100 \mu \mathrm{M}$ DNP, and $200 \mu \mathrm{M}$ 4NP. Similarly BOD removal efficiency was decreased with increasing concentrations of the uncouplers. However, the BOD removal rate at the maximum concentration of each uncoupler used remained at more than $60 \%$ of the control, even though the biomass production was almost zero. Of particular interest was that the BOD removal efficiency in the presence of 200 $\mu \mathrm{M} 4 \mathrm{NP}$ was decreased only by approximately $20 \%$ as compared to the control level.

The aforementioned results indicate that CCCP and DNP

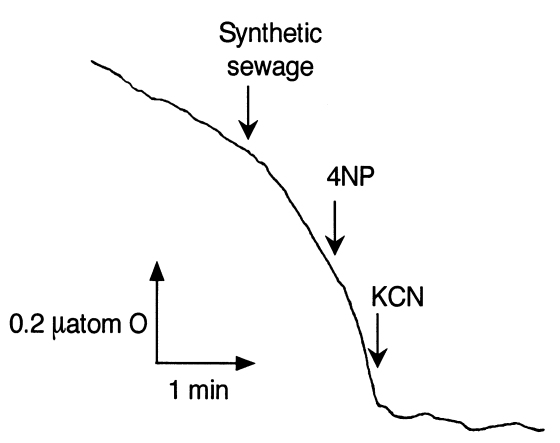

Fig. 1. DO uptake profile of activated sludge in response to addition of synthetic sewage $(20 \mu \mathrm{l}), 4 \mathrm{NP}(200 \mu \mathrm{M})$, and $\mathrm{KCN}(1 \mathrm{mM})$.

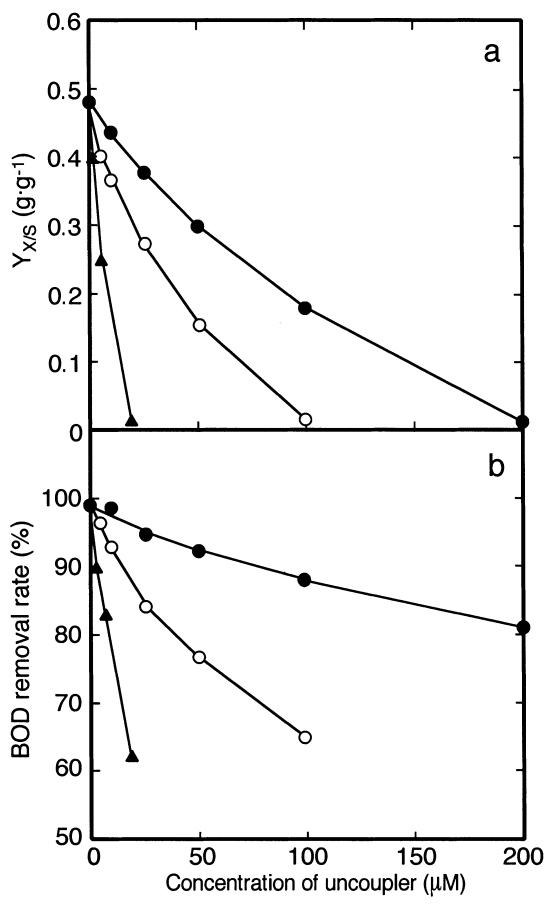

Fig. 2. Effects of CCCP (triangles), DNP (open circles), and 4NP (closed circles) on biomass yield and BOD removal rate in laboratory-scale activated sludge reactors. (a) biomass yield coefficient; (b), BOD removal rate.

are much stronger uncouplers than 4NP. However, the use of 4NP seemed to be more appropriate from a practical point of view, because it brought about less of a decrease in BOD removal efficiency. Therefore, 4NP and its relatives, $2 \mathrm{NP}, 3 \mathrm{NP}, 3 \mathrm{CP}$, and $4 \mathrm{CP}$, were further tested for their effects on biomass production and BOD removal efficiency. As shown in Table 2, all of the chlorophenols and nitro-

Table 2. Effects of different uncouplers on biomass production and BOD removal rate in batch cultures of activated sludge ${ }^{\mathrm{a}}$.

\begin{tabular}{lccc}
\hline Additive & $\begin{array}{c}\text { Biomass produced } \\
\left(\Delta X, \mathrm{mg} \mathrm{dry} \mathrm{wt} \cdot l^{-1} \cdot \mathrm{d}^{-1}\right)\end{array}$ & $\begin{array}{c}\text { BOD removal rate } \\
\left(\Delta S, \mathrm{mg} \cdot l^{-1} \cdot \mathrm{d}^{-1}\right)\end{array}$ & $\begin{array}{c}\text { Average } Y_{\mathrm{X} / \mathrm{s}} \\
\left(\mathrm{mg} \cdot \mathrm{mg}^{-1}\right)\end{array}$ \\
\hline $3 \mathrm{CP}$ & $91 \pm 28$ & $520 \pm 27(82)^{\mathrm{c}}$ & 0.18 \\
$4 \mathrm{CP}$ & $91 \pm 29$ & $518 \pm 25(81)$ & 0.18 \\
$2 \mathrm{NP}$ & $34 \pm 29$ & $508 \pm 35(80)$ & 0.067 \\
$3 \mathrm{NP}$ & $83 \pm 57$ & $510 \pm 20(80)$ & 0.16 \\
$4 \mathrm{NP}$ & $29 \pm 22$ & $498 \pm 37(78)$ & 0.059 \\
No addition & $316 \pm 191$ & $636 \pm 11(99)$ & 0.49
\end{tabular}

${ }^{a}$ Data shows the averages and standard deviations of three to four different batch cultures. The concentration of uncoupler added was 200 $\mu \mathrm{M}$ in all cases.

${ }^{\mathrm{b}}$ Expressed as the MLSS increased.

${ }^{\mathrm{c}}$ Figures in parentheses show the percentage removal rate. 
Table 3. Respiratory enzyme activities in activated sludges cultivated with different uncouplers ${ }^{\mathrm{a}}$.

\begin{tabular}{|c|c|c|c|c|c|}
\hline \multirow{2}{*}{ Uncoupler added } & \multicolumn{5}{|c|}{ Specific activity (U.g protein ${ }^{-1}$ ) } \\
\hline & $\begin{array}{l}\text { NADH oxidase } \\
\left(\mathrm{NADH} \rightarrow \mathrm{O}_{2}\right)\end{array}$ & $\begin{array}{l}\text { NADH dehydrogenase } \\
\text { (NADH } \rightarrow \text { DCIP) }\end{array}$ & $\begin{array}{l}\text { Succinate dehydrogenase } \\
\text { (PMS mediated) }\end{array}$ & $\begin{array}{l}\text { Nitrate reductase } \\
\quad\left(\mathrm{NO}_{3} \rightarrow \mathrm{NO}_{2}\right)\end{array}$ & $\begin{array}{l}\text { Denitrification } \\
\left(\mathrm{NO}_{3} \rightarrow \mathrm{N}_{2}\right)\end{array}$ \\
\hline $3 \mathrm{CP}$ & 75.2 & 1,020 & 64.5 & 226 & 144 \\
\hline $4 \mathrm{CP}$ & 77.0 & 1,160 & 70.5 & 302 & 167 \\
\hline $2 \mathrm{NP}$ & 70.8 & 1,090 & 70.2 & 284 & 152 \\
\hline $3 \mathrm{NP}$ & 70.8 & 1,090 & 70.2 & 284 & 152 \\
\hline $4 \mathrm{NP}$ & 76.6 & 1,320 & 72.3 & 267 & 140 \\
\hline No addition & 75.6 & 1,120 & 75.0 & 275 & 156 \\
\hline
\end{tabular}

${ }^{a}$ Data shows the averages of two to three different determinations. The concentration of uncoupler added was $200 \mu \mathrm{M}$ in all cases.

phenols tested exhibited similar effects on both biomass production and BOD removal efficiency. Comparison of these uncouples suggested that the effectiveness for biomass reduction was most pronounced in the following order: $4 \mathrm{NP}>2 \mathrm{NP}>3 \mathrm{NP}>3 \mathrm{CP}=4 \mathrm{CP}$. For instance, the addition of $200 \mu \mathrm{M} 4 \mathrm{NP}$ resulted in a reduction in the biomass yield to less than $10 \%$ compared to the control test, while the BOD removal efficiency with $4 \mathrm{NP}$ remained at approximately $80 \%$ of the control level.

Effects of on respiratory activities, total counts, and quinone content

Respiratory enzyme activities were measured for activated sludges during one week of cultivation with the chlorophenol- and nitrophenol-type uncouplers (Table 3). No marked differences were noted between sludges cultivated with and without the uncouplers in NADH oxidase, NADH dehydrogenase, succinate dehydrogenase, and denitrification enzyme activities.

Total counts and quinone contents were also measured in activated sludges with the five different uncouplers and compared to the control without any chemical additive (Table 4). As expected, the sludges with uncouplers exhibited lower total counts and quinone concentrations than the control sludge. These effects were most pronounced in the sludge with 4 NP.

These data suggest that the addition of the chlorophenoland nitrophenol-type uncouplers in a short period has no or a minor effect on the respiratory activities of activated sludge but exerts severe effects on the level of biomass produced.

\section{Effects of $4 N P$ during a long operation period}

The effects of 4NP on the characteristics of activated sludge were further studied in a prolonged period of operation. As shown in Fig. 3, the inhibitory effect of 4NP on bio- mass production was constant during the first 2 weeks from the start of dosing. Thereafter, however, this effect gradually diminished with time and had almost vanished at the end of experiment (after 4 weeks). Despite no or little effect of uncoupler on biomass production at this stage, the BOD removal efficiency was not restored to the same level found in the reactor without 4NP added. During the first week, more than $60-80 \%$ of the uncoupler added remained in the supernatant. The remainder was possibly absorbed by the sludge flocs. In contrast, 4NP was not detectable in the culture after 4 weeks of operation, suggesting that it was degraded by the existing microorganisms at this stage.

Changes in microbial community structure in response to the prolonged addition of 4NP were monitored by quinone profiling (Fig. 4). The sludge sampled one week from the start of 4NP dosing (Fig. 4b) was similar in quinone profiles to the sludge before the addition (Fig. 4a), where Q-8 and MK-8 $\left(\mathrm{H}_{4}\right)$ were the major quinones detected. On the other hand, the sludge sampled at the end of operation (Fig. 4c) gave a distinct quinone pattern from the former two sludges, where increases in Q-10 and Q-9 contents were remarkable in particular. Thus, the $D$ value between the sludges at the

Table 4. Total counts and quinone contents in batch cultures of activated sludges with different chemical uncouplers ${ }^{\mathrm{a}}$.

\begin{tabular}{lcccc}
\hline \multirow{2}{*}{$\begin{array}{c}\text { Uncoupler } \\
\text { added }\end{array}$} & $\begin{array}{c}\text { Total count } \\
\left(\times 10^{9} \text { cells ml }\right.\end{array}$ & \multicolumn{3}{c}{ Quinone content $\left(\mathrm{nmol} \mathrm{ml}^{-1}\right)$} \\
\cline { 3 - 5 } $3 \mathrm{CP}$ & $2.7 \pm 0.4$ & $3.49 \pm 0.18$ & $1.87 \pm 0.19$ & $1.62 \pm 0.17$ \\
$4 \mathrm{CP}$ & $2.8 \pm 0.8$ & $3.49 \pm 0.16$ & $1.88 \pm 0.10$ & $1.61 \pm 0.17$ \\
$2 \mathrm{NP}$ & $2.2 \pm 0.1$ & $3.41 \pm 0.18$ & $1.90 \pm 0.19$ & $1.51 \pm 0.15$ \\
$3 \mathrm{NP}$ & $2.8 \pm 0.3$ & $3.52 \pm 0.16$ & $1.88 \pm 0.09$ & $1.64 \pm 0.24$ \\
$4 \mathrm{NP}$ & $2.1 \pm 0.4$ & $3.39 \pm 0.10$ & $1.89 \pm 0.10$ & $1.50 \pm 0.11$ \\
No addition & $3.2 \pm 0.6$ & $4.02 \pm 0.20$ & $2.10 \pm 0.20$ & $1.92 \pm 0.17$ \\
\hline
\end{tabular}

${ }^{a}$ Data shows the averages and standard deviations of four different determinations. 


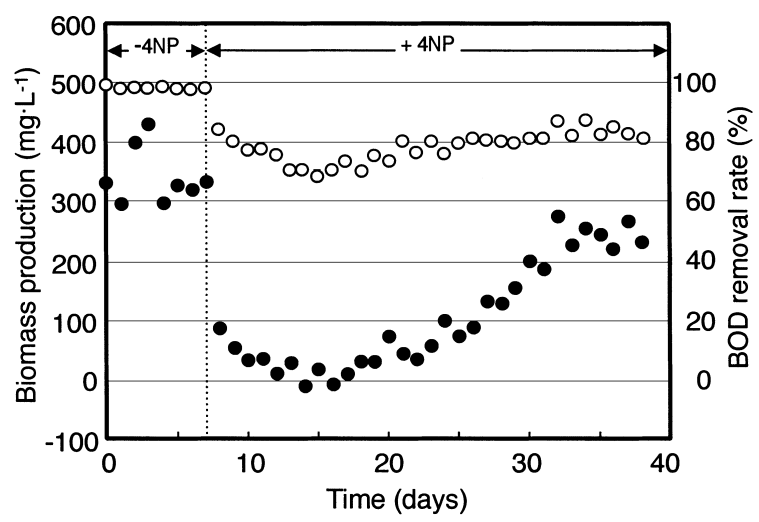

Fig. 3. Effects of 4NP on biomass yield (closed circles) and BOD removal rate (open circles) in a laboratory-scale activated sludge reactor during a long period of operation. The reactor was operated without 4NP during the first week and then fed with $200 \mu \mathrm{M}$ $4 \mathrm{NP}$ in every batch cycle.

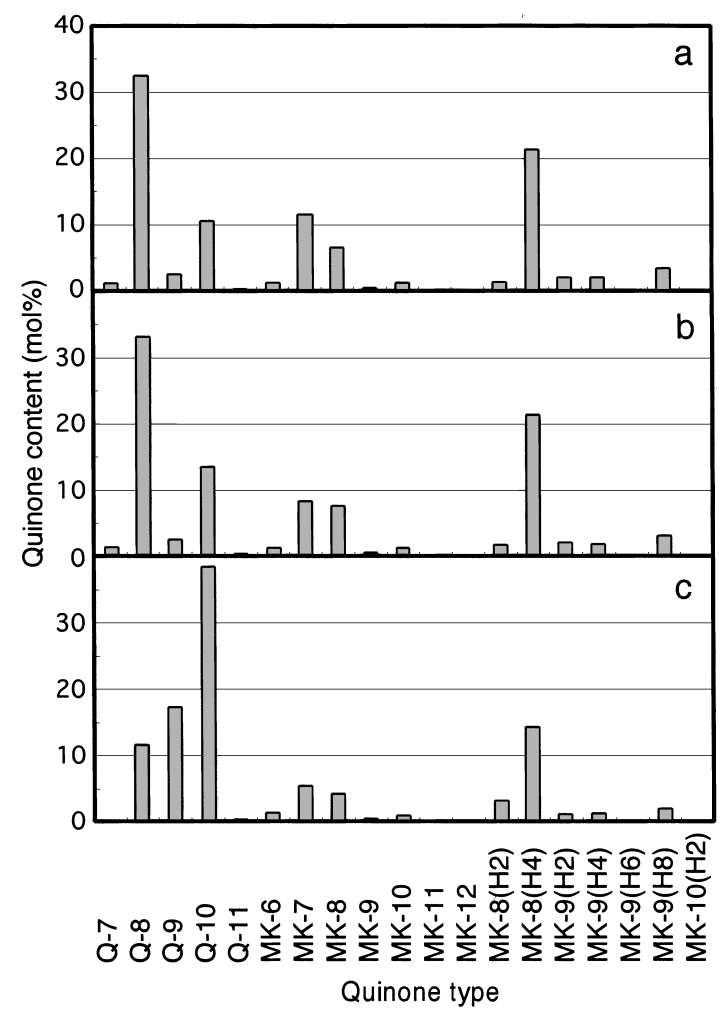

Fig. 4. Changes in quinone profiles of activated sludge during a long period of operation with 4NP. (a), control sludge just before addition of 4NP: (b), sludge after 4 days of operation with 4NP; (c) sludge after 31 days of operation with $4 \mathrm{NP}$.

early and final stages of operation was approximately $40 \%$, suggesting that a significant microbial population shift took place as a result of the prolonged uncoupler dosing.

\section{Discussion}

The chemiosmotic theory of energy transduction ${ }^{26,27)}$ offers a comprehensive understanding of the action of uncouplers on oxidative phosphorylation ${ }^{9}$. The metabolic uncoupler facilitates the transmembrane movement of protons or other compensatory ions and reduces the proton motive potential difference across the cytoplasmic membrane, thereby dissipating the chemical energy. Thus, the biomass production in microbial cultures is much lowered in the presence of the uncoupler without a significant decrease in substrate oxidation efficiency. Recently, several investigators have applied this biochemical basis to concur the problem of how to reduce excess biomass in activated sludge systems ${ }^{5,6,21-23)}$.

As reported in this study, we have confirmed that the addition of an uncoupler to activated sludge batch cultures can significantly reduce biomass production. The BOD removal efficiency as well as biomass production also exhibit a decreasing trend with increasing concentrations of the uncoupler, but the decrease in the former efficiency is much less significant than that in the latter. For example, at a $4 \mathrm{NP}$ concentration of $200 \mu \mathrm{M}$, the biomass yield was reduced to less than $10 \%$ compared to the control test, while BOD removal efficiency with $4 \mathrm{NP}$ remained approximately $80 \%$ of the control level. Also we found that such a level of the chlorophenols and nitrophenols had no or little effect on the respiratory enzyme activities of activated sludge.

Although the biomass reduction in the activated sludge process as an effect of uncoupler dosing has been demonstrated, information about what type of uncouplers is more suitable for practical use has been scanty before this study. One of the interesting observations in this study is that the biomass reduction efficiency differed among uncouplers having different $\mathrm{p} K_{\mathrm{a}}$ values. In terms of chemistry, the stronger acids have smaller $\mathrm{p} K_{\mathrm{a}}$ values (see Table 1). Excluding CCCP and DNP, the effectiveness for biomass reduction was most pronounced in the following order: $4 \mathrm{NP}>2 \mathrm{NP}>3 \mathrm{NP}>3 \mathrm{CP}=4 \mathrm{CP}$. In view of this finding, it is likely that uncouplers with a lower $\mathrm{p} K_{\mathrm{a}}$ value has a higher potential to reduce biomass production. Nevertheless, the application of a stronger uncoupler has more potential risk of reducing substrate oxidation efficiency and the resultant deterioration of the effluent quality. In terms of practical use, therefore, one should pay careful consideration to the kind and concentration of uncouplers to be applied.

A major problem of the application of chemical uncouplers for activated sludge processes is the effects of longterm dosing. As reported herein, the positive effect of 4NP on biomass production gradually diminished with time and 
had almost vanished after 4 weeks from the start of its continuous addition. One of the most plausible reasons for this is that a long-term addition of uncoupler to an activated sludge reactor brings about a significant population shift to microbiota fully acclimated to the uncoupler. Our finding that the 4NP added was no longer detected after 4 weeks of operation suggests that 4NP-degrading bacteria became predominant and degraded the uncoupler at this stage. The biodegradation of nitrophenols in activated sludge and similar wastewater treatment systems has recently been reported $^{2,25,29)}$. Several investigators have isolated chlorophenol- and nitrophenol-degrading bacteria and identified them as members of the genera Arthrobacter ${ }^{3,7,15)}$, Burkholderia $^{3)}$, Nocardia $^{7)}$, Pseudomonas $^{28,34)}$, Ralstonia ${ }^{3,33)}$, Rhodococcus $^{34)}$, and Sphingomonas ${ }^{4}$. The microbial community analysis by quinone profiling in this study showed that the predominant bacteria in the activated sludge reactor were changed from those with Q-8 and MK- $8\left(\mathrm{H}_{4}\right)$ to those with Q-10 during a long-term operation with 4NP. In light of the available information about quinone systems of bacteria and activated sludges ${ }^{10-14)}$, the possible sources of Q-8, MK-8( $\left.\mathrm{H}_{4}\right)$, and Q-10 are thought to be members of $\beta$ Proteobacteria, Actinobacteria, and $\alpha$-Proteobacteria, respectively. It is most likely that the long-term addition of 4NP to the activated sludge reactor resulted in a population shift to 4NP-degrading $\alpha$-Proteobacteria such as Sphingomonas species ${ }^{4}$. However, it is clearly necessary to further study what phylogenetic and physiological groups of bacteria become predominant in 4NP-acclimated activated sludge.

In conclusion, the addition of chemical uncouplers to activated sludge reactors is effective in reducing excess biomass production, but this positive effect is questionable over a long period of operation. Thus, whether or not the uncoupler method is significant for practical use should be more carefully considered in future studies.

\section{References}

1) American Public Health Association. 1992. Standard methods for water and wastewater, 5th ed., American Public Health Association, Washington, D.C.

2) Bhatti, Z.I., H. Toda and K. Furukawa. 2002. p-Nitrophenol degradation by activated sludge attached on nonwovens. Water Res. 36: $1135-1142$.

3) Bhusha, B., A. Chauhan, S.K. Samanta and R.K. Jain. 2000. Kinetics of biodegaradation of $p$-nitrophenol by different bacteria. Biochem. Biophys. Res. Commun. 274: 626-630.

4) Cassidy, M.B., H. Lee, J.T. Trevors and R.B. Zablotowicz. 1999. Chlorophenol and nitrophenol metabolism by Sphingomonas sp. UG30. J. Ind. Microbiol. Biotechnol. 23: 232-241.

5) Chen, G.H., H.K. Mo, S, Saby, W.K. Yip and Y. Liu. 1999. Min- imization of activated sludge production by chemical situmulated energy spilling. Water Sci. Technol. 42: 189-200.

6) Chen, G.H., S. Saby, M. Djafer and H.K. Mo. 2001. New approaches to minimize excess sludge in activated sludge systems. Water Sci. Technol. 44: 203-208.

7) Hanne, L.F., L.L. Kirk, S.M. Appel, A.D. Narayan and K.K. Bains. 1993. Degradation and induction specificity in actinomycetes that degrade $p$-nitrophenol. Appl. Environ. Microbiol. 59: $3505-3508$.

8) Hartree, E.F. 1972. Determination of protein. Modification of the Lowry method that gives a linear photometric response. Anal. Biochem. 48: 422-427.

9) Heytler, P.G. 1980. Uncouplers of oxidative phosphorylation. Pharmacol. Ther. 10: 461-472.

10) Hiraishi, A. 1988. Respiratory quinone profiles as tools for identifying different bacterial populations in activated sludge. J. Gen. Appl. Microbiol. 34: 39-56.

11) Hiraishi, A. 1999. Isoprenoid quinones as biomarkers of microbial populations in the environment. J. Biosci. Bioeng. 88: 449460.

12) Hiraishi, A., Y. Morishima and J. Takeuchi. 1991. Numerical analysis of lipoquinone patterns in monitoring bacterial community dynamics in wastewater treatment systems. J. Gen. Appl. Microbiol. 37: 57-70.

13) Hiraishi, A., Y. Ueda, and J. Ishihara and T. Mori. 1996. Comparative lipoquinone analysis of influent sewage and activated sludge by high-performance liquid chromatography and photodiode array detection. J. Gen. Appl. Microbiol. 42: 457-469.

14) Iwasaki, M. and A. Hiraishi. 1998. A. new approach to numerical analyses of microbial quinone profiles in the environment. Microbes Environ. 13: 67-76.

15) Jain, R.K., J.H. Dreisbach and J.C. Spain. 1994. Biodegradation of $p$-nitrophenol via 1,2,4-benzenetriol by an Arthrobacter sp. Appl. Environ. Microbiol. 60: 3030-3032.

16) Khan, S.T., Y. Horiba, M. Yamamoto and A. Hiraishi. 2002. Members of the family Comamonadaceae as primary poly(3hydroxybutyrate-co-3-hydroxyvalerate)-degrading denitrifiers in activated sludge as revealed by a polyphasic approach. Appl. Environ. Microbiol. 68: 3206-3214.

17) King, M.T. and G. Drews 1973. The function and localization of ubiquinone in the NADH and succinate oxidase systems of Rhodopseudomonas palustris. Biochim. Biophys. Acta 305: 230248.

18) Kristjansson, J.K. and T.C. Hollocher. 1980. First practical assay for soluble nitrous oxide reductase of denitrifying bacteria and a partial kinetic characterization. J. Biol. Chem. 255: 704-707.

19) Krulwich, T.A., P.G. Quirk and A.A. Guffanti. 1990. Uncouplerresistant mutants of bacteria. Microbiol. Rev. 54: 52-65.

20) Lewis, K., V. Naroditskaya, A. Ferrante and I. Fokina. 1994. Bacterial resistance to uncouplers. J. Bioenerg. Biomembr. 26: 639-646.

21) Liu, Y. 2000. Reduced growth yield of activated sludge in organic protonophore-containing batch culture. Microb. Ecol. 39: 168173.

22) Low, E.W. and H.A. Chase. 1998. The use of chemical uncouplers for reducing biomass production during biodegradation. Water Sci. Technol. 37: 399-402.

23) Low, W.W., H.A. Chase, M.G. Milner and T.P. Curtis. 2000. Uncoupling of metabolism to reduce biomass production in the activated sludge process. Water Res. 34: 3204-3212. 
24) Mannheim, W., W. Stieler, G. Wolf and R. Zabel. 1978. Taxonomic significance of respiratory quinones and fumarate respiration in Actinobacillus and Pasteurella. Int. J. Syst. Bacteriol. 28: 7-13.

25) Melgoza, R.M. and G. Buitron. 2001. Degradation of $p$-nitrophenol in a batch biofilter under sequential anaerobic/aerobic environments. Water Sci. Technol. 44: 151-157.

26) Mitchell, P. and J. Moyle. 1965. Stoichiometry of proton translocation through the respiration chain and adenosine triphosphatase system of rat liver mitochondria. Nature 208: 147.

27) Nichollus, D.G. 1982. Bioenergetics: An introduction to the chemiosmotic theory. Academic Press, New York.

28) Qureshi, A., S.K. Prabu and H.J. Purohit. 2001. Isolation and characterization of Pseudomonas strain for degradation of 4nitrophenol. Microbes Environ. 16: 49-52.

29) Ray, P., M. Ait Oubelli and C. Loeser. 1999. Aerobic 4-nitrophenol degradation by microorganisms fixed in a continuously working aerated solid-bed reactor. Appl. Microbiol. Biotechnol. 45: 428-435.

30) Rocher, M., G. Roux, G. Goma, A.P. Begue, L. Louvel and J.L. Rols. 2001. Excess sludge reduction in activated sludge processes by integrating biomass alkaline heat treatment. Water Sci. Technol. 44: 437-444.
31) Roser, D.J. 1980. Ethidium bromide: a general purpose fluorescent stain for nucleic acid in bacteria and eucaryotes and its use in microbial ecology studies. Soil Biol. Biochem. 12: 329-336.

32) Saby S., M. Djafer and G.H. Chen. 2002. Feasibility of using a chlorination step to reduce excess sludge in activated sludge process. Water Res. 36: 656-666.

33) Schenzle, A., H. Lenke, P. Fischer, P.A. Williams and H. Knackmuss. 1997. Catabolism of 3-nitrophenol by Ralstonia eutropha JMP 134. Appl. Environ. Microbiol. 63: 1421-1427.

34) Shinozaki, Y., N. Kimura and T. Nakahara. 2002. Difference in degrading $p$-nitrophenol between indigenous bacteria in a reactor. J. Biosci. Bioeng. 93: 512-514.

35) Urata, K. and T. Satoh. 1982. Periplasmic location of nitrous oxide reductase in a photodenitrifier, Rhodopseudomonas sphaeroides forma sp. denitrificans. Plant Cell Physiol. 23: 11211124.

36) U.S. National Library of Medicine. TOXNET, Hazardous Substances Data Bank, http://toxnet.nlm.nih.gov/cgi-bin/sis/htmlgen?HSDB.htm.

37) Yasui, H., K. Nakamura, S. Sakuma, M. Iwasaki and Y. Sakai. 1996. A full-scale operation of a novel activated sludge process without excess sludge production. Water Sci. Technol. 34: 395404. 